\title{
Improving food security through the urban farming workshop for disaster risk reduction: evidence from Jogoyudan Village, Yogyakarta as a Resilient City
}

\author{
Lexi Jalu Aji ${ }^{*}$, Siswo Hadi Sumantri ${ }^{1}$ Yuli Subiyakto ${ }^{2}$, Mir'atul Azizah $^{1}$, and Annisa Rahmawati $^{1}$ \\ ${ }^{1}$ Disaster Management Study Program, National Security Faculty, Republic of Indonesia Defense University. IPSC Sentul Area, \\ Bogor, West Java, Indonesia \\ ${ }^{2}$ Management Department, Gadjah Mada University, Yogyakarta, Indonesia
}

\begin{abstract}
This study aims to determine the effect of the implementation of urban farming workshops on food security of Jogoyudan Village residents supporting the concept of Yogyakarta as a Resilient City as a disaster risk reduction. This study is a quasi-experimental study using a nonequivalent pretest-posttest control group design. This study involved 200 residents in 4 RWs (Neighborhoods) in Jogoyudan Village as the research sample selected by cluster random sampling. RW 08 and RW 10 as the experimental group, while RW 11 and RW 12 as the control group. The research data were collected through assessment instruments in the form of pretest and posttest that were analyzed quantitatively, as well as using the method of observation and documentation. The result of this study indicates that the implementation of the urban farming workshop has a positive effect on improving the understanding level of food security of the people in Jogoyudan Village as evidenced by the value of the Wilcoxon test of $0.000(\alpha>0.05)$ and the Mann-Witney test of $0.000(\alpha>0.05)$. In addition to that, the urban farming workshop can also provide participants with farming skills, which can facilitate greater and easier access for food which is the main indicator of food security, as attested by the experimental group in Jogoyudan Village who was able to independently make hydroponic installations at their homes. This shows that the urban farming workshop can be one of the ways toward disaster risk reduction supporting the realization of Yogyakarta as a Resilient City.
\end{abstract}

\section{Introduction}

Population density is a challenge that has to be addressed in the consideration of disaster mitigation. The emergence of potential disasters due to population density is caused by several triggers, one of them being dense settlements that extend to riverbanks [1]. The village on the banks of the Code River is an example of a disaster-prone settlement located in the middle of Yogyakarta City. Every year, a flood occurs from the Code River due to heavy rains that overtops the riverbanks. In 2010, there was even an eruption of Mount Merapi which spewed cold lava into the river and caused massive flooding. One of the affected villages was Jogoyudan Village [2].

Flood may cause various kinds of derivative disasters, one of them being food disasters. When a disaster occurs, the food availability decreases while the community needs post-disaster increase [3]. The consequences of floods might immobilize daily activities and might cause economic losses. Furthermore, disrupted food production will increase the price of food due to a decrease in food supply [4]. The need for food will arise along with the increasing population growth in a specific area [5]. This may escalate the community's vulnerability to disasters. To prevent this, public awareness is needed to maintain food security.

Food security is a highly complex issue in national development and is mainly a top priority in development [6], it even has become one of the main agendas in the Sustainable Development Goals (SDGs) forum [7]. According to Law No. 18 of 2012 concerning Food, food security is the fulfillment of food for households, carried out by the availability of sufficient food, both in quantity and quality, safe and affordable in a sustainable manner [8]. Based on this concept, there are 3 aspects of food security, namely, 1) availability, 2) affordability and 3) quality and safety [9].

Based on data collected by the Global Food Security Index (GFSI) 2020, Indonesia's food security level is ranked 65 out of 113 countries. It is ranked 34th for availability, 55th for affordability, and 89th in terms of quality and safety [9]. Given the fact that Indonesia is an agricultural country with vast and abundant fertile soils,

\footnotetext{
* Corresponding Author: lexijalu@gmail.com
} 
Indonesia's food security rank in terms of affordability, as well as quality and safety is considered low.

As stated by the report of the Ministry of Agriculture Republic Indonesia (2021), part of the reason for Indonesia's low ranking in two aspects of food security was caused by natural disasters and environmental damage (non-natural disasters) that occurred in Indonesia. The occurrences of natural disasters in Indonesia contributed to the disruption in the food distribution chain and the damage to agricultural land, resulting in the community's affordability aspect diminished. The unbounded environmental pollution and excessive use of chemicals in agriculture caused the low quality and safety aspects of food security in Indonesia [10]. On top of that, based on research [11], the Covid-19 pandemic has impacted food security as it hampered the distribution, availability, affordability, and stability of food.

As one of the cities proclaimed as a resilient city, Yogyakarta City needs to fix this food problem. The concept of a Resilient City is a city that can recover quickly in the face of disasters (Adiyoso, 2018). The disaster management paradigm has evolved from "fatalistic responsive" that is oriented to emergency responses to "proactive preparedness" that focuses early on thorough preparation. This paradigm requires both the government and the community to jointly undertake disaster risk reduction efforts [12]. Consequently, the government and the people of Yogyakarta City are obliged to put efforts to lower disaster risk concerning the threat of food disasters.

The affordability aspect has an assessment indicator in the form of the community's ability to access food. If the community can produce food independently, the community's access to food will be easier, assessing the affordability aspect better. The affordability aspect also has an indicator of the people's understanding of food diversity. The better the community's understanding of food diversity, the higher the affordability aspect's value [13]. Meanwhile, the quality and safety aspect is related to the nutritional quality of food and its safety. The better the nutritional quality and safety of the food consumed by the community, the higher the quality and safety aspect will be. In addition to that, this same aspect also has indicators of community understanding regarding nutrition and food safety [9]. Based on this explanation, assistance that can improve skills, as well as people's understanding of food security, is needed.

A workshop is an educational program designed to teach students theoretical and practical skills that can be used in everyday life functions [14]. The results of research conducted by Lahami (2021) show that workshops can improve students' competence in conceptual and practical skills in agricultural management [15].

Jogoyudan Village is a dense urban settlement located on the banks of Code River in the middle of Yogyakarta. Many people living in this village are not owner-occupiers and almost the entire land surface has been covered by buildings and concrete, making it difficult for residents to garden and generate livestock [16]. One farming method that can be applied in urban areas is Hydroponics. Hydroponics is one of the urban farming systems that does not require fertile soils and can be applied in narrow areas [17].

In reality, the Gowongan Village Government has developed programs related to food counseling for the community, but the evaluation of these activities has not shown significant results on the level of food security in Jogoyudan Village. The counseling given to the community focuses more on food nutrition and health education; it has not yet reached the field of food security [18].

Based on the information obtained in the above description, we conducted this study using the title "Improving Food Security Through Urban Farming Workshop for Disaster Risk Reduction: Evidence from Hogoyudan Village, Yogyakarta, Indonesia". The purpose of this study was to measure the effect of the urban-farming workshop on food security in Jogoyudan Village for disaster risk reduction. The formulated hypothesis of this research is that the Urban Farming Workshop can improve food security in Jogoyudan Village for disaster risk reduction.

\section{Method and Data}

This quantitative research used a Quasi Experiment research model with a Nonequivalent Pretest-Posttest Control Group Design. The sampling technique used in this study was Cluster Random Sampling [19].

This research was conducted in 2019 in Jogoyudan Village, Gowongan Sub-district, Jetis District, Yogyakarta City. The population of the study was the residents of Jogoyudan Village and using a sample of 4 (four) RWs (Neighborhoods) whose areas are on the banks of the Code River, namely RW 08 and RW 12 as the experimental group, while RW 10 and RW 11 as the control group. For the determination of sample size, this study referred to Isaac and Michael's reference table [20]. The independent variable in this study was the urban farming workshop which was applied to the experimental group, while the control group used the Gowongan Village government's food training program. The dependent variable in this study was the food resilience level of the residents of Jogoyudan Village.

The data of this study included data on the understanding level of food security as well as urbanfarming skills. Data on urban-farming skills were collected through observation and documentation that were analyzed descriptively. Meanwhile, data on the understanding level of food security were collected through pretest and posttest assessment instruments that were analyzed with a statistically inferential method.

The prerequisite tests carried out by this study conducted a normality test of the data using the Shapiro Wilk test, while the homogeneity test was used to determine the data using the Levene test. Based on the results of the prerequisite test, the Mann-Whitney U test and the Wilcoxon test were used for the inferential statistical test [21]. The Wilcoxon test was used to test the value of the level of understanding of food security before and after the workshop, while the Mann-Witney test was used to test the difference in the value of the level of 
understanding of food resilient in the experimental group and the control group.

\section{Result and Discussion}

\subsection{Description of Research Activities}

Jogoyudan Village is located at the banks of Code River in Gowongan Sub-district, Jetis District, Yogyakarta City. Jogoyudan Village has 5 RWs (Neighborhoods), namely RW 08, RW 09, RW 10, RW 11, and RW 12. In this study, RW 08 and RW 10 were used as the experimental group, while RW 11 and RW 12 as the control group.

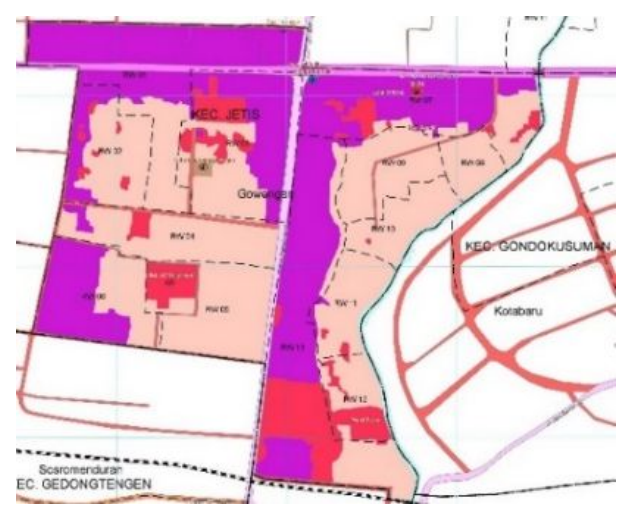

Fig. 1. Gowongan Village Administration Map

The treatment for the experimental group was given in the form of an urban farming workshop. The urban farming workshop activity consists of 3 activities, specifically 1) teaching activity, 2) hands-on/practical activity, and 3) a study visit to PT. Indmira. RW 08 carried out activity 1 and activity 2 on Friday, July 15th, 2019, while RW 10 carried out the activities on Friday, July 22nd, 2019. The teaching materials for the experimental group started by providing a brief introduction to urban farming and the concept of food security through food diversification, then followed by wick-hydroponic practice activities.

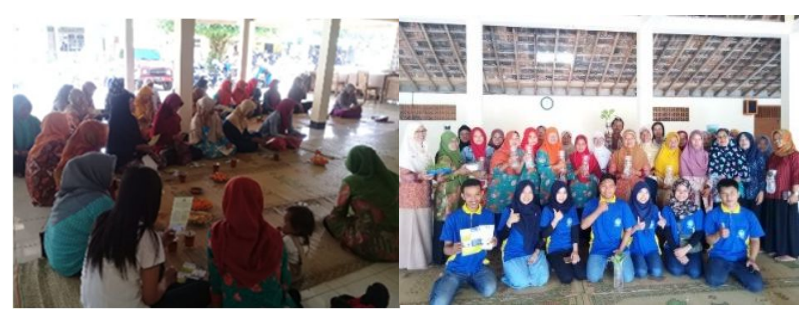

Fig. 2. Documentation of Urban Farming Workshop Activities

After the participants were able to practice hydroponics, we continued activity 3 by performing a study visit to PT. Indmira, which was held all together on Saturday, July 23rd, 2019. PT Indmira is a research company in the agri-complex field engaged in the business of organic vegetable products using the hydroponic method.

In the control group, the training activities were successfully carried out without the intervention of the researcher. The training activities were conducted by the Gowongan Village Government following the village program plan in the form of food nutrition counseling related to public health.

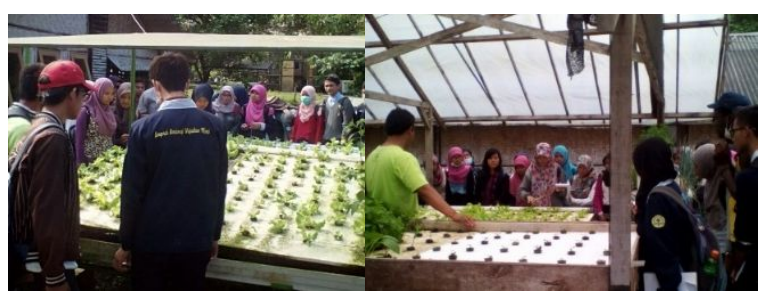

Fig. 3. Documentation of Industrial Visits

\subsection{Understanding Level of Food Security}

The total number of families in RW 08 consists of 132 families, while RW 10 consisting a total of 136 families. In this study, one person from each family was selected as a representative for the research sample. Based on Isaac and Michael's table (Jakni, 2017), the minimum sample size with a significance of $5 \%$ is 100 .

Table 1. Result of Homogeneity Test Value of Understanding Level of Food Security.

\begin{tabular}{|l|l|l|l|l|}
\hline \multirow{2}{*}{$\begin{array}{l}\text { Descriptive } \\
\text { Analysis }\end{array}$} & \multicolumn{2}{|l|}{ Experimental Class } & \multicolumn{2}{l|}{ Control Class } \\
\cline { 2 - 5 } & Pretest & Posttest & Pretest & Posttest \\
\hline $\begin{array}{l}\text { Number of } \\
\text { Participants }\end{array}$ & 100 & 100 & 100 & 100 \\
\hline Minimum & 25,00 & 65,00 & 20,00 & 50,00 \\
\hline Maximum & 55,00 & 100,00 & 60,00 & 100,00 \\
\hline Mean & 39,75 & 83,80 & 40,70 & 76,75 \\
\hline
\end{tabular}

Based on the results of descriptive analysis, the average value of the level of understanding of food security in the experimental group increased from 39.75 (pretest) to 83.80 (posttest) with a difference of 44.05 increase in value. The average value of the level of understanding of the control group also increased from 40.70 (pretest) to 76.75 (posttest) with a difference of 36.05 increase in value. This shows that there is a difference in the increasing deviation value between the experimental group and the control group.

Table 2. Normality Test Results Values of Understanding Level of Food Security.

Tests of Normality

\begin{tabular}{|c|c|c|c|c|c|c|}
\hline \multirow[t]{2}{*}{ Class } & \multicolumn{3}{|c|}{ Kolmogorov-Smirnov } & \multicolumn{3}{|c|}{ Shapiro-Wilk } \\
\hline & Statistic & df & Sig. & Statistic & df & Sig. \\
\hline $\begin{array}{l}\text { Postest } \\
\text { Exp. } \\
\end{array}$ & .160 & 100 & .000 & .950 & 100 & .001 \\
\hline $\begin{array}{l}\text { Postest } \\
\text { Control }\end{array}$ & .212 & 100 & .000 & .929 & 100 & .000 \\
\hline
\end{tabular}

For the normality test, the above table showed that the significance value of the posttest results in the experimental and control groups were both less than 0.05 $(\alpha<0.05)$, this tells that the research data were not normally distributed. Since the research data were not normally distributed, non-parametric tests were used for inferential tests. The inferential tests performed as 
mentioned used the Wilcoxon test and the Mann-Witney test.

Table 3. Wilcoxon Test Results in Value of understanding Level of Food Security.

Test Statistics $^{\mathrm{a}}$

\begin{tabular}{|l|l|}
\hline & PostestEx - PretestEx \\
\hline Z & $-8.810^{\mathrm{b}}$ \\
Asymp. Sig. (2-tailed) & .000 \\
\hline
\end{tabular}

a. Wilcoxon Signed Ranks Test

b. Based on negative ranks.

The Wilcoxon test was applied to see if there was a significant difference in the average value between the average pretest value and the average posttest value of the experimental group (Creswell, 2017). The results of the Wilcoxon test showed a significance value of $0.000(\alpha>$ 0.05 ), which means that there is a significant difference in the average value between the average pretest value and the average posttest value of the experimental group.

Table 4. Mann-Whitney Test Results Value of Understanding Level of Food Security.

Test Statistics ${ }^{\text {a }}$
\begin{tabular}{|l|l|}
\hline & PostestResult \\
\hline Mann-Whitney U & 2886.000 \\
Wilcoxon W & 7936.000 \\
Z & -5.264 \\
Asymp. Sig. (2-tailed) & .000 \\
\hline
\end{tabular}

a. Grouping Variable: Postest

After the Wilcoxon test, we conducted the MannWitney test to find a significant difference in the average score between the average posttest scores of the experimental group and the control group [21]. The results of the Mann-Witney test showed a significance value of $0.000(\alpha>0.05)$, meaning that there was indeed a significant difference in the average value between the average posttest value of the experimental group and the average posttest value of the control group.

\subsection{Urban farming Skills}

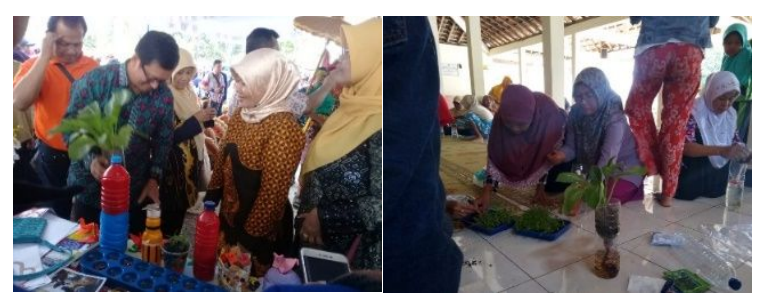

Fig. 4. Documentation of Urban Farming Workshop Activities

Based on the results of observations made in the field, residents of RW 08 and RW 10 as the experimental group who received treatment with the urban farming workshop were able to practice the given training. The urban farming workshop in the form of hydroponic training was successfully carried out by some residents of RW 08 and RW 10 as evidenced by the following documentation
The residents demonstrated great enthusiasm during the training, as seen from the number of participants in the urban farming workshop from RW 08 and RW 10 that reached the total amount of 124 people, exceeding the minimum target required of 100 participants. In addition to being introduced to hydroponics, the residents were also brought into the farming techniques of vertical gardens and fruit plants in pots.

The urban farming workshop effectively developed the residents' skills in managing plants. One reason was that after the training, of the 124 participants who attended the workshop, 76 participants were succeeded and continued to make hydroponics independently in their respective homes. Although constrained by limited land, residents took the initiative to use the walls of their houses and yard fences to put hydroponics. There was even one resident who could build hydroponic installation in their yard, with documentary evidence as follows:

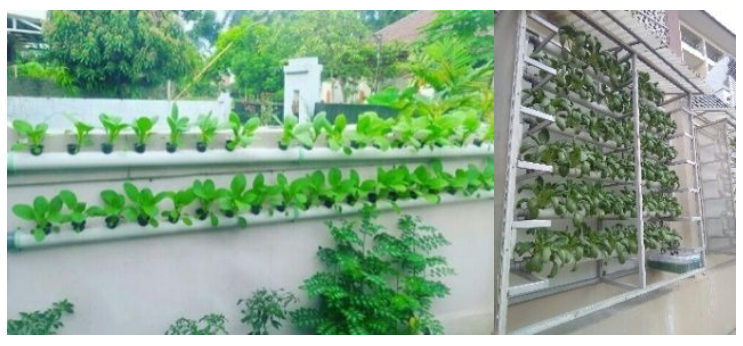

Fig. 5. Residents' Hydroponic Installation Documentation

\subsection{Discussion}

Population density is one of the challenges in disaster risk management [1]. The dense settlements on the banks of the Code River in Yogyakarta City are one example of disaster-prone settlements due to overcrowding. Every year in that place, a flood occurs due to the overflowing banks of the Code River. The most severe flooding happened during the 2010 eruption of Mount Merapi, the material from the eruption of Mount Merapi filled the river and caused massive flooding in the settlements around the Code River. One of the affected villages was Jogoyudan Village [2].

Floods can cause various kinds of derivative disasters, one of them being food disasters [3]. Food disasters may occur due to the immobilization of people's daily activities when a flood disaster occurs. The inhibition of food distribution and production activities causes scarcity and increases in food prices [4]. In addition, food problems can arise along with an increase in population that is not accompanied by a rising in food production. The decrease in agricultural land also decreases the quantity of food. Therefore, it is necessary to increase the capacity and understanding of the community to maintain food security [5].

It is such an irony that Indonesia's food security was ranked 65 out of 113 countries, knowing that Indonesia is an agricultural country with abundant fertile soils and a tropical climate. Indonesia's low ranking in food security is due to Indonesia's low score in terms of food accessibility and food quality and safety [9]. 
The Ministry of Agriculture of Indonesia reported that Indonesia's low ranking in two aspects of food security was caused by natural disasters and environmental damage. The occurrences of natural disasters in Indonesia contributed to the disruption in the food distribution chain and the damage to agricultural land, resulting in the community's affordability aspect diminished. Furthermore, the widespread environmental damage caused the food quality and safety aspects to below [10].

As one of the cities proclaimed as a resilient city, Yogyakarta City needs to fix the potential for foods disasters. The disaster management paradigm has evolved from fatalistic responsiveness oriented to emergency response to proactive preparedness that focuses early on efforts to reduce disaster risk [12]. This shifting paradigm requires both the government and the community to jointly undertake disaster risk reduction efforts.

Training using a workshop method is considered effective in improving skills. A workshop is an educational program designed to teach students theoretical and practical skills that can be used in everyday life functions [14]. Providing workshops with material on urban farming has the potential to improve community skills for farming in urban areas, this will affect aspects of affordability and quality as well as food security in the community.

The indicators for improving the aspect of food affordability consist of two things, namely 1) the level of community ability in accessing food and 2) the level of public understanding of the diversity of food. The aspect of food quality and safety also has two indicators, namely 1 ) the level of quality of food nutrition and food safety obtained by the community and 2) the level of public understanding about nutrition and food safety [9].

In this study, the urban farming workshop given to the experimental group consisted of 3 activities, namely 1) teaching activity, 2) hands-on/practical activity, and 3) a study visit. In the teaching activity, the material given was an introduction to urban farming and hydroponics as a method of urban farming. Workshop participants were also given the material on the concept of food security, introduction to food nutrition, and food diversification programs as a solution to food problems and disasters.

Based on research data obtained using pretest and posttest instruments, the implementation of an urban farming workshop can increase the average value of the level of understanding of food security in the experimental group. The average score increased from 39.75 (pretest) to 83.80 (posttest) with a difference of 44.05 increase in value. The increase in value was significant, as evidenced by the results of the Wilcoxon test on the pretest and posttest scores of the experimental group which obtained a significance value of $0.000(\alpha>$ $0.05)$. From this result, it is concluded that the increase in the average value of the level of understanding in the experimental group shows that the urban farming workshop can improve indicator number 2 on aspects of affordability and quality, and safety.

The urban farming workshop has proven to be more effective in increasing the level of understanding of community food security, compared to the training provided by the Gowongan Village government. This is supported by the result of the average posttest score obtained by the experimental group (83.80) which is higher than the control group (76.75) with an average difference of 7.05 points. The difference in average values is significant, validated by the results of the Mann-Witney test that obtained a significance value of $0.000(\alpha>0.05)$.

Apart from being able to increase the level of understanding of food security, the urban farming workshop was also expected to build urban farming skills in the community. Accordingly, it was expected to increase the first indicator on the availability aspect in terms of increasing the ability of the community to access food, along with the third indicator on quality and safety aspect, in terms of increasing the level of quality of food nutrition and food safety obtained by the community.

The practical activity was implemented by providing a hands-on experience and a study visit to workshop participants. The practical activity was conducted by practicing making hydroponics. The hydroponic method used in this study was the wick technique. The wick technique is one of the simplest hydroponic techniques that does not require electricity and complicated installation. The materials for conducting the wick technique only require used goods, namely bottles and used cloth. In addition to low production costs, practicing hydroponics using the wick technique is more environmentally friendly because it can reduce waste that may pollute the environment.

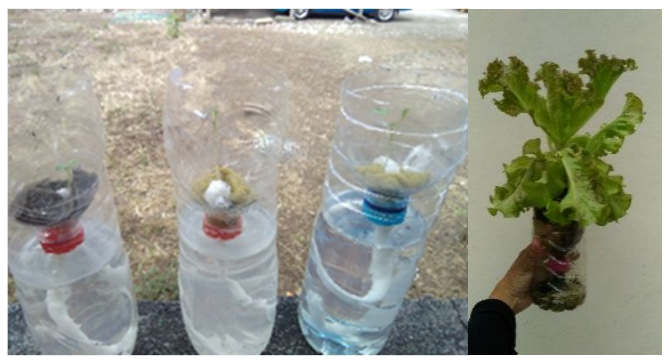

Fig. 6. Hydroponics with Wick Technique

The study visit was carried out by visiting PT. Indmira, a company engaged in the organic vegetable industry, let the participants have in-depth learning about hydroponics. The participants were permitted to carry out several activities. For starters, they were introduced to various hydroponic techniques other than Wick Technique, such as the Floating Raft Technique and the Nutrient Film Technique (NFT) that were documented in Fig. 3. We also provided the know-how on how to market hydroponic products to participants that were conducted with the aim that after the workshop, apart from being able to grow crops using hydroponics, participants can also grow their crops independently and can market their products.

The results of observations and research documentation showed that the urban farming workshop can improve the community's skills in producing food independently, meaning that people may be able to gain greater and easier access to food sources. This was attested by all 124 participants in the urban farming 
workshop who could make hydroponics using the wick technique as documented in Fig. 4.

Based on the results of observations and research documentation post-follow up the urban farming workshop, there were 76 people out of 124 workshop participants who succeeded and continued to make hydroponics independently at home. There was even one resident who was able to build hydroponic installations using Floating Raft Techniques and NFT techniques that could be seen on the documentation in Fig. 5. This also proves that limited land does not become a limiting factor in agricultural farming.

Based on the data provided and analysis conveyed, this leads to the conclusion that the urban farming workshop can improve the first and second indicators of food security. For the first indicator, namely the affordability aspect, people can produce food independently resulting in them getting greater and easier access to food. As for the second indicator, the community can have better quality and safety of the food they produce themselves, which can increase the quality and safety aspect of food security.

The two value increases in terms of affordability and quality and safety aspects regarding food security prove that the implementation of urban farming workshops can effectively improve the food security of the people in Jogoyudan Village. This will furthermore reduce vulnerability and increase community capacity concerning the threat of food disasters. In addition to that, this research also supports the realization of Resilient City which is a program of the Yogyakarta City government. By conducting the urban farming workshop, it has become one of the steps to reduce disaster risk that can be applied to people living in urban areas and dense settlements.

\section{Conclusion}

Based on the analysis conveyed, it can be concluded that the urban farming workshop has a positive effect on improving the understanding level of food security of the people in Jogoyudan Village as validated by the results of the Wilcoxon test of $0.000(\alpha>0.05)$ and the MannWitney test of $0.000(\alpha>0.05)$. In addition to that, the urban farming workshop has also provided participants with farming skills, that will furthermore facilitate greater and easier access to food which is the main indicator of food security, as attested by the experimental group in the Jogoyudan Village who were able to construct hydroponic installations independently at their homes. Finally, this study shows that the urban farming workshop can be one of the ways toward disaster risk reduction supporting the realization of the Resilient City concept in Yogyakarta.

\section{References}

1. L. J. Aji, D. P. Meiliasari, R. K. Apriyadi, S. Maarif, H. Sumantri, PENDIPA J. Sci. Educ. 6, 64 (2022).

2. T. Harahap, Sudayono, D. Kristiadi, J. Tekno Glob. 5, 29 (2016).

3. U. Azmiyati, J. Social Science and Education. 3, (2019).

4. Y. Oktari, J. Social Science and Education. 2, (2018).

5. Y. Purwaningsih, J. Ekon. Pembang. 9, 1 (2008).

6. A. R. Quisumbing, L. R. Brown, H. S. Feldstein, L. Haddad, C. Peña, Food Nutr. Bull. 17, 1 (1996).

7. A. Suryana, Toward Sustainable Indonesian Food Security 2025: Challenges and Its Responses Achmad (2014).

8. Ministry, of Health, Bul. Data And Inf. Window. health Semester I, (2015).

9. GFSI, Regional Report: Asia Pacific (2021).

10. Ministry of Agriculture, Performance Report Food Availability and Insecurity (2021).

11. N. A. Fitriah, Impact of the Covid-19 Pandemic on Indonesian Food Security: An Exploratory Research, Bogor Agricultural University (2021).

12. Z. D. G. Raja, H. Hendarmawan, S. Sunardi, J.L Environment. And the Geol Disaster G. 8, 103 (2017).

13. I. Rural, L. Through, B. Productive, Nature 544, 1 (2008).

14. R. H. Kurniawan, Manag. Account. Res. J. 04, 16 (2019).

15. M. A. G. Lahami, J. Educ. Technol. Curriculum, Learn. Commun. 1, 13 (2021).

16. N. R. P. Ayodiya, J. Pembang. Wil. Kota 10, 22 (2014).

17. E. Sugianto, Hydroponics, Altitude Requirements, Temperature, Relative Humidity, Sunlight 1 st ed. (Gramedia, Jakarta, 2008)

18. T. Rahayu, L. J. Aji, A. Suta, A. Hergani, A. Fitria, R. N. Utami, S. V. Vidyaningsih, Int. Inventory. Innov. Competence. 2, 54 (2017)

19. Sugiyono, Educational Research Mrthods (Qualitative, Quantitative And R\&D) (Alfabeta, Bandung, 2019)

20. Jakni, Experimental Research Methodology in Education (Alfabeta, Bandung, 2017)

21. J. Creswell, Riset Educational Research: Planning, Implementation, and Evaluation of Qualitative \& Quantitative Research (Learning Library, Yogyakarta, 2017) 